\title{
Genetic Algorithms Optimised Chemical Reactors Network Application: Hydrogen Emissions Performance of a V2527 Engine
}

\author{
C. Leong ${ }^{1}$, S. Blakey ${ }^{2}$ \\ ${ }^{1}$ Independent researcher. \\ ${ }^{2}$ Department of Mechanical Engineering, Faculty of Engineering, University of Sheffield.
}

\begin{abstract}
Emissions from hydrogen combustion in aircraft engines are one of the concerns of this future alternative fuel. Full scale engine tests are costly. Modelling may provide insight into emissions formation process and reduce the costs. However, availability of combustor data (geometry and flow splits) in the public domain is limited. A technique, namely Genetic Algorithms optimised Chemical Reactors Network (GACRN) was implemented to search for the flow splits of a V2527 engine combustor. Then the optimised model was used to study the impact on $\mathrm{NO}_{x}$ emissions from hydrogen combustion with a conventional engine. A further GA optimisation to flow splits was conveyed to show the necessary works to make hydrogen a feasible alternative fuel with minimum changes to the engine. The final results demonstrated that GACRN is able to provide support in redesigning combustors to specific fuels.
\end{abstract}

Keywords Chemical Reactors Network; Genetic Algorithms; Hydrogen; $\mathrm{NO}_{\mathrm{x}}$

\section{INTRODUCTION}

Flight tests on hydrogen fuels usually involve overall modifications to the whole aircraft [1]. As nearly all the current fleets are kerosene based, even a small percentage of these fleets chosen for hydrogen flight studies would be costly. Also, the use of hydrogen may involve brand new aircraft and engine designs. This paper is intended to show an alternative way to analyse one part of this challenge, hydrogen emissions, by using simulation. The Genetic Algorithms optimised Chemical Reactors Network (GACRN) [2] has shown that it is possible to reverse engineer the combustor flow splits and reactor sizes by matching the experimental data and forward predict alternative fuels emissions in an Auxiliary Power Unit (APU). Therefore it was applied to convey the study of $\mathrm{NO}_{x}$ emissions in a LandingTakeoff (LTO) cycle of hydrogen as a drop-in fuel in a V2527 engine and as an alternative fuel in a modified V2527 engine.

\section{Methodology OF GACRN IN HYDROGEN COMBUSTION}

The geometry and the air flow splits of any combustors in aircraft engines are confidential business information. Some of this information may be found in literature albeit to a very limited degree. Since the International Civil Aircraft Organisation (ICAO) requires all engine manufacturers to submit new engines emissions performance on $\mathrm{CO}, \mathrm{NO}_{\mathrm{x}}$ and un-burnt hydrocarbons (UHC) in the landing-take off cycle as a regulation [3], it has become an assessable emissions data bank for aircraft engine combusted with kerosene. Together with thermodynamics conditions of the V2527 engine by F.Svensson et al. [4-6], these data provided the starting point for the GACRN to reverse engineer the flow splits and chemical reactors sizes. The V2527 combustor was modelled as a CRN of Perfectly Stirred Reactors (PSR), cf. Fig. 1. The assumption was that the mixing effect of fluid did not play a role in the combustion process and the combustion was only controlled by the chemical kinetics. This is valid because the jet entrainments of gas turbine combustors were designed to induce instant mixing to achieve near complete combustion, control of emissions, and evenly distributed turbine inlet temperatures. The GA mimics the principle of natural selection and adaptation, i.e. selfdirected trial and error. Like nature, this trial and error process is done as a whole population of individuals; therefore the GA is a multiple locations search method. The flow splits and volume splits (PSR sizes) were the variables for the GA to alter in order to match the emissions data from the ICAO data bank.

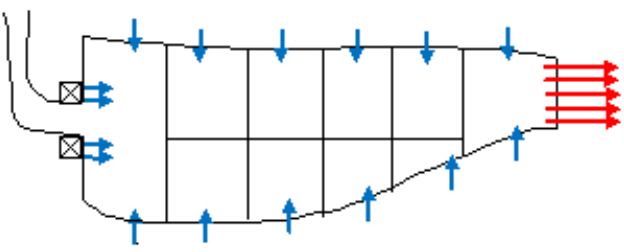

Figure 1. Schematic of the V2527 10 PSR CRN; blue arrows are compressed air and red arrows are flue gases.

\section{RESULTS AND DISCUSSIONS}

The optimisation process was started with matching the ICAO emissions data with kerosene fuel. Fig. 2 shows that the trends of both $\mathrm{NO}_{x}$ and $\mathrm{CO}$ are reasonably consistent with ICAO data. The perfect fit of $\mathrm{NO}_{x}$ emissions to ICAO data indicated good accuracy of temperatures and residence times in the CRN. The emissions of UHC were negligibly small; therefore any discrepancies between the calculated UHC emissions and ICAO data have trivial impact on the model. 


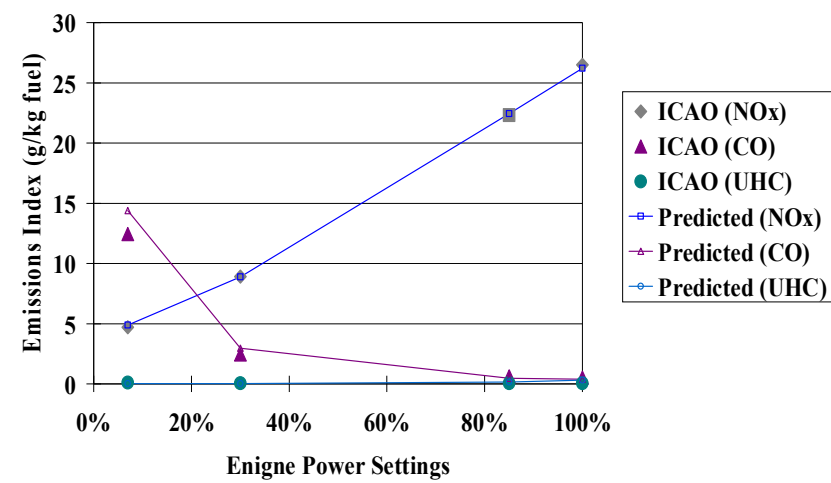

Figure 2. Engine Emissions Data in the LTO cycle; solid labels taken from the ICAO data bank, hollow labels calculated by the V2527 CRN.

Fig. 3 shows that hydrogen combustion in a V2527 engine produced more $\mathrm{NO}_{\mathrm{x}}$ emissions than kerosene combustion. In fact, in both of the higher engine power settings, the hydrogen combustion increased $\mathrm{NO}_{\mathrm{x}}$ emissions by more than $60 \%$. Since the V2527 combustor was not designed for hydrogen, the GA was applied to adjust the flow splits and volume of PSRs in order to minimise the $\mathrm{NO}_{x}$ emissions. The GA found a modified hydrogen combustor with more than $70 \%$ of the combustor core air mass flow rate entrained into the first half of the combustor. Due to the fuel-lean combustions, $\mathrm{NO}_{\mathrm{x}}$ emissions from the engine were reduced to negligibly low levels (<1ppm). Fig. 4 shows the temperature distribution along the length of the combustor at $85 \%$ and $100 \%$ power conditions of all three fuel/combustor scenarios. Formation of $\mathrm{NO}_{x}$ increases exponentially at temperatures above $1800 \mathrm{~K}$, so a temperature difference of $100 \mathrm{~K}$ between hydrogen and kerosene combustion at peak temperatures has increased $\mathrm{NO}_{x}$ by more than half. On the other hand, the modified $\mathrm{H}_{2}$ combustor benefited from lean burn condition, the flame temperatures were capped below $1600 \mathrm{~K}$. As a result, only insignificant amounts of $\mathrm{NO}_{x}$ were formed in the process.

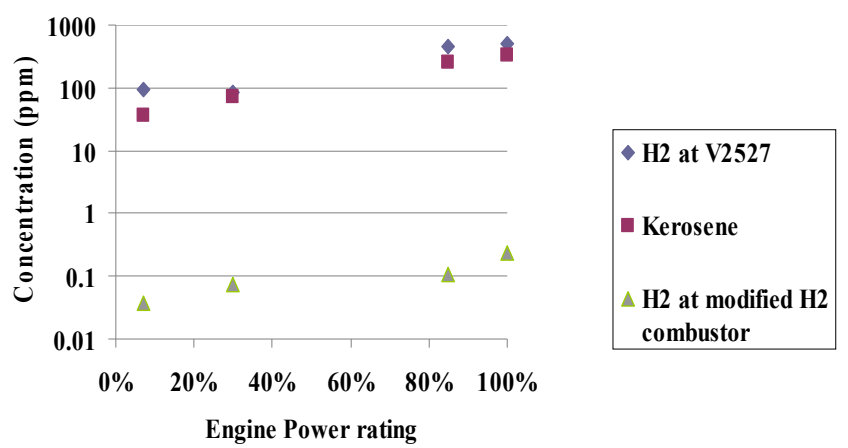

Figure 3. Comparison of $\mathrm{NO}_{x}$ emissions of different fuels and combustors.

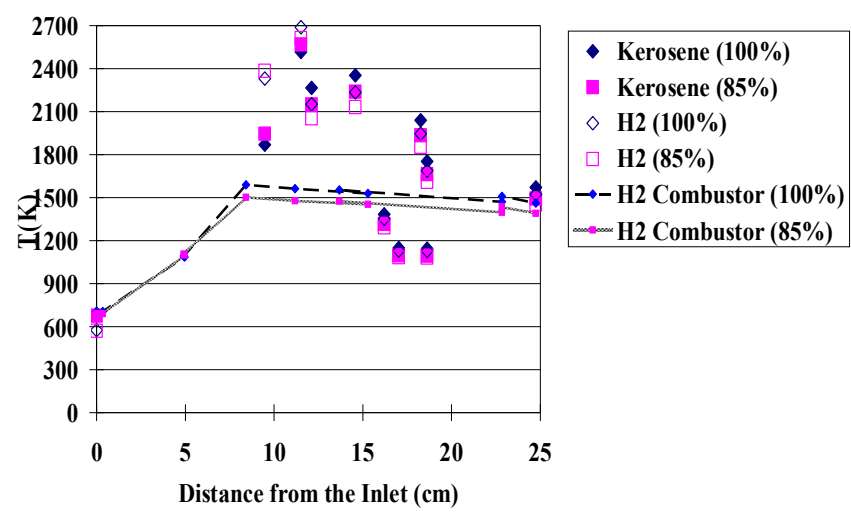

Figure 4. Temperature distributions along the length of V2527 combustor.

\section{CONCLUSIONS}

The GACRN demonstrated the reverse engineering of flow/volume splits of a CRN to match ICAO emissions data of a V2527 engine. The optimised model showed that high $\mathrm{NO}_{\mathrm{x}}$ emissions in hydrogen combustion would be experienced without adjustment to the engine. Furthermore, the GACRN revealed its potential to redesign combustors to improve combined emissions performance of different fuels and support construction of an emissions data bank of alternative fuels in different engines.

\section{ACKNOWLEDGEMENTS}

This work was completed as part of Chris Leong's PhD in Mechanical Engineering under the supervision of Prof. Chris Wilson. This work was funded by the EU FP6 programme, AERONET II. Data on V2527 engine performance was provided by Fredrick Svensson, formally of FOI, the Swedish Defence Research Agency. This paper is also dedicated to the memory of Prof. Chris Wilson, a colleague and a friend.

\section{REFERENCES}

1. D. Verstraete. "The Potential of Liquid Hydrogen for Long Range Aircraft Propulsion" PHD Thesis. School of Engineering (Cranfield University, 2009)

2. C. C. Leong, L. J. Rye, S. Blakey and C. W. Wilson. Reverse Engineering Gas Turbine Emission Performance: Applied to an Aircraft Auxiliary Power Unit. ASME Turbo ExpoJune 14-18 2010, Glasgow, UK, (2010)

3. ICAO Data Bank

4. F. Svensson and R. Singh. Effects of Using Hydrogen on Aero Gas Turbine Pollutant Emissions, Performance and Design. Proceedings of ASME Turbo Expo 2004, June 14 -17, Vienna, Austria, 2004.

5. F. Svensson, A. Hasselrot and J. Moldanova. "Reduced Environmental Impact by Lowered Cruise Altitude for Liquid Hydrogen-Fuelled Aircraft". Aerospace Science and Technology, 2004, 8, $307-320$.

6. S Blakey. Performance Data for the V2527-A5 Engine, Personal Communication with F. Svensson. 